\title{
INTRAOPERATIVE COMPLICATIONS ARE SIGNIFICANTLY LESS IN PCNL IN THE TREATMENT OF LARGE RENAL CALCULI : A PROSPECTIVE RANDOMIZED CONTROLLED TRIAL
}

\author{
SYED ALFASANI ${ }^{1}$, ZAMANUL ISLAM BHUIYAN ${ }^{2}$
}

${ }^{1}$ Department of surgery, UHC, Kaliakoir, Gazipur, Former student (MS-thesis) of NIKDU, ${ }^{2}$ Department of Urology, National Institute of Kidney Diseases \& Urology, Dhaka-1207

\begin{abstract}
:
Objective: To compare the safety and efficacy of percutaneous nephrolithotomy (PCNL) and open surgery in the treatment of patients having large kidney stone $(>2 \mathrm{~cm})$.

Materials \& Methods: A Randomised controlled clinical trial (RCT) of 80 patients diagnosed with kidney stone disease admitted in the NIKDU during the period of Jan' to Dec'2009 were divided conveniently into two groups. Intervention was done in the form PCNL(40) and open surgery (40).

Clinical outcome like, peroperativecomplications, durationof surgery, mean hospital stay, convalescence period, amount of analgesia required to relief pain, stone clearance rate were reviewed and compared between the groups.

There was no significant difference in preoperative variables such as age,sex, stone size in $\mathrm{cm}$, stone number- single/multiple and stag horn Stone.

Results: There were statistically significant difference in the parameters between the groups, ( $P C N L$ vs open surgery [mean $\pm S D]$ ): duration of operation (min), $97.90 \pm 24.89$ vs $136.62 \pm 23.54$, postoperative hospital stay (days), $4.77 \pm 3.98$ vs $9.55 \pm 3.65$, mean time return to work (days) , $3.09 \pm 1.21 v s 6.25 \pm 1.53$, ( $p$ value is $<0.001$ ).

Intraoperative complications like bleeding requiring blood transfusion are significantly lower in PCNL (11 cases 34.1\%) than in open surgery( 18 cases 45.0\%), (Chi-square = 4.82; $p=0.049)$.

Conclusion: PCNL is relatively safe \& better treatment option than open surgery in the treatment of large renal calculi, It has definite advantages of statistically less peroperative bleeding and lower morbidity.
\end{abstract}

Keywords: PCNL (Percutaneous nephrolithotomy), RCT(Randomised controlled clinical trial), open surgery, Intraoperative complication.

Bangladesh J. Urol. 2014; 17(2): 71-74

\section{Introduction}

Kidney stone disease is existing among mankind since the earliest record of civilization. Hippocrates described the renal stone as first disease of the kidney[1]. High incidence of renal stone disease is found in U.S.A, U.K, Scandinavian countries, Mediterranean countries, portion of the Malayan peninsula and China. Low incidence is found in central and south America, most of Africa and part of Australia [2]. (stoller et al. 2000).

Correspondence: Syed Alfasani, Department of surgery, UHC, Kaliakoir, Gazipur.Former student (MS-thesis) of NIKDU, Dhaka
Now four minimally invasive treatment modalities are available for the treatment of kidney stones such as ESWL (Extra corporeal shock wave lithotripsy). Percutaneous nephrolithotomy (PCNL), retrograde ureteroscopic intra renal surgery and laparoscopic stone surgery[3]. (Lingeman et al. 2002).Now a days all uncomplicated and most of the complicated renal stones are treated by percutaneous method as a routine procedure in the western set up, although the technique is still evolving in the developing country like ours[4]. 
Open stone surgery is an old and established procedure. In Bangladesh larger kidney stones are mostly treated by open surgery because of poor socioeconomic context[5].

PCNL was not available in Bangladesh till January 2000. In National Institute of Kidney Diseases \& Urology, this technique has been regularly undertaken since 2004 . The present study is the first prospective randomized work conducted in NIKDU, Dhaka to compare the outcome like efficacy, morbidity and convalescence among PCNL \& open surgery. An increasing awareness of this technique by both patients \& referring physicians has raised important questions regarding the safety and efficacy of the percutaneous methods Vs standard renal surgery.

If any superiority of treatment by PCNL can be provided or shown that this is relatively safe than the method can further be popularized among the Urologist of our country and this study may be the basis of further research in this field.

\section{Materials \& Methods}

This Randomised controlled clinical trial (RCT), initially includes all the patient with kidney stone disease that were admitted in urology department of NIKDU during the period of Jan'2009 to Dec'2009.Total 80 Patients were divided conveniently into two groups PCNL(40) and open surgery (40). Randomization was done by taking consecutive samples. Intervention was done in the form of PCNL and open surgery.

The cases were selected with the Inclusion criteria having Stone size more than $2 \mathrm{~cm}$, Functioning kidney with Sterile urine and the exclusion criteria is renal failure,pregnancy, uncontrolled bleeding disorder, congenital / acquired skeletal abnormalities and Infected urine

All patients were evaluated by history, clinical examination and Investigations having similar protocol. Before operation, each patient of two groups were evaluated and compared for age and sex of the patients, size, number, location of the stones and pelvicalyceal dilatation.

Open surgery was performed through standered flank incision with or without rib resection. A standered PCNL was performed with subcostal single puncture in 29 units and double puncture in 2 units. Initially pneumatic, later on ultrasonic lithotripsy was used . 18 Fr nephrostomy tube was left in each puncture and D-J stent (6Fr) was kept in ureter. Radiological evaluation was done postoperatively. Patient who were completely cleared of stones were considered stone free.

Patients were followed monthly for 3 months where, 9 patients were missed in PCNL group resulting in 31 patients. Again history, clinical examination and Investigations like urine routine and culture, plain X-ray KUB were done and post PCNL data were recorded .

Statistical analysis was done meticulously by SPSS for windows-14 version program. Data was presented as mean $\pm S D$. probable value of less than 0.05 was considered significant. Test of significance was done by student t-test , z-test and chi-square test.

\section{Results}

Preoperative characteristics (mean $\pm \mathrm{SD}$ ) were as follows: (PCNL vs open surgery): age, $44.48 \pm 10.31$ vs $45.22 \pm 15.53$ yrs; sex, (male/female), 20/11vs 24/16; stone size in cm,3.07 $\pm 0.93 \mathrm{vs} 3.44 \pm 1.09$; stone numbersingle/multiple, $26(83.9 \%) / 5(16.1 \%)$ vs $26(65.0 \%) /$ 14(35.0\%); stag horn Stone,5(16.1\%)vs 4(10.0\%). There were no significant difference between the two groups $(p>0.05)$.

Table -I

Preoperative characteristics.

\begin{tabular}{lcc}
\hline Characteristics & \multicolumn{2}{c}{ Name of Operation } \\
\cline { 2 - 3 } & PCNL & Open surgery \\
\hline No. of patients & 31 & 40 \\
Age in year (Mean \pm SD) & $44.48 \pm 10.31$ & $45.22 \pm 15.53$ \\
Sex (male/female) & $20 / 11$ & $24 / 16$ \\
Stone size in cm (Mean \pm SD) & $3.07 \pm 0.93$ & $3.44 \pm 1.09$ \\
Stonenumber- Single/ & $26(83.9 \%) /$ & $26(65.0 \%) /$ \\
Multiple & $5(16.1 \%)$ & $14(35.0 \%)$ \\
Stag horn Stone & $5(16.1 \%)$ & $4(10.0 \%)$ \\
\hline
\end{tabular}

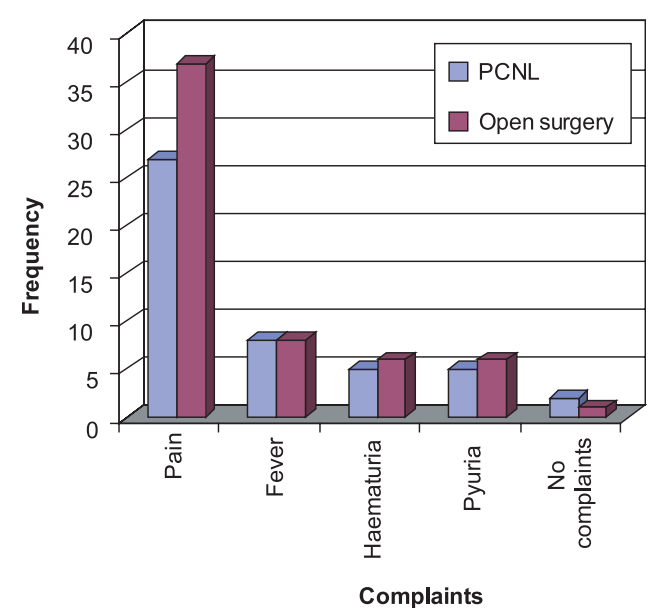

Fig.-1: Chief complaints of the patients 
Alfasani \& Bhuiyan

Table-II

Type of intra-operative complications

\begin{tabular}{lcc}
\hline Type of complications & $\begin{array}{r}\mathrm{PCNL} \\
\mathrm{N}=31\end{array}$ & $\begin{array}{c}\text { Open surgery } \\
\mathrm{N}=40\end{array}$ \\
\hline Bleeding & 11 & 18 \\
Colon Injury & 1 & 0 \\
Pleural Injury & 0 & 3 \\
RenalPelvis Injury & 0 & 2 \\
\hline
\end{tabular}

Table-III

Intra-operative complications

\begin{tabular}{lcc}
\hline Complications & $\begin{array}{c}\mathrm{PCNL} \\
\mathrm{N}=31\end{array}$ & $\begin{array}{c}\text { Open surgery } \\
\mathrm{N}=40\end{array}$ \\
\hline Yes & $12(37.3 \%)$ & $23(57.5 \%)$ \\
No & $19(67.7 \%)$ & $17(42.5 \%)$ \\
\hline
\end{tabular}

Chi-square $=4.82 ; p=0.049$

The intraoperative complications like bleeding requiring blood transfusion was recorded in $11(34.1 \%)$ cases in PCNL group, and 18 cases in (45.0\%) in open surgery group ( $P$ value is $<.05)$. In open surgery group, there was $3(7.5 \%)$ pleural injury and $2(5.0 \%)$ renal pelvis injury, where as $1(3.2 \%)$ colon injury was observed in PCNL group, as because this was very early experience of PCNL in this institute. Here, intraoperative complications are significantly lower in PCNL group than in open surgery group. In case of empty cells in a table Fisher's exact test was done other wise chi-square test was done.

Here in PCNL, 5 patients needed 1 unit, 4 patients 2 unit \& 2 patients needed 3 units of blood transfusion. It is postulated that the aggressive treatment of large stone burden with multiple puncture is associated with great blood loss, although only two cases with multiple tracts were included in yhe present study.

\section{Discussion:}

The present study has been designed to compare the outcome of PCNL and open surgery for the management of renal stone disease more than $2 \mathrm{~cm}$ in size. After counseling, taking consent and considering the inclusion and exclusion criteria finally 80 Patients were selected and divided into two groups, PCNL(40) and open surgery (40). In complete follow up 9 patients were missed in PCNL group resulting in 31 patients.

The mean age of the patients was 44.48 years $(\mathrm{SD} \pm 10.31)$ in $\mathrm{PCNL}$ group and 45.22 years (SD \pm 15.53$)$ in open surgery. The age of the patient was statistically insignificant $(>0.05)$. The age range of the present study is more or less comparable with the study done by Assimos et al. [6]. in 1991, (age:23 to 79 years) \& by Brannen et al[7] in 1985, (age:21 to 94 years). The highest age is higher in those countries is due to long life expectancy of that country and elderly people attending in the clinic.

The mean size of the stone in PCNL group was $3.07 \mathrm{~cm}$ (SD \pm 0.94$)$ and in open surgery was $3.44 \mathrm{~cm}(\mathrm{SD} \pm 1.09)$. The size of the stone in both groups were analysed and found no significant difference ( $p>05$ ). In a study by Wong YC, [8]. in 1998,stone size was recorded between 2 to $7.5 \mathrm{~cm}$ which is almost similar to the size of stone of present study.

In PCNL vs open surgery group ,11 (34.1\%) cases vs 18 cases (45.0\%) required blood transfusion. Regarding other injuries, there was $3(7.5 \%)$ pleural injury and 2 (5.0\%) renal pelvis injury resulted in open surgery group. Neither of this injuries occurred in PCNL group. 1 (3.2\%) colon injury was happened in PCNL group, , which was not observed in open surgery group. However, intraoperative complications are significantly lower in PCNL group than in open surgery group.

In study of Al-kohlany et al. [9] in 2005, reported blood transfusion were required in $33 \%$ cases in open surgery and $14 \%$ cases in PCNL group. In this study intraoperative complications like bleeding, injuries to pleura, vessels or ureter were $7(16.3 \%)$ cases in PCNL vs $17(37.8 \%)$ cases in open surgery which closely correlates with the other study. Rassweilier et al.[10] in 2000 showed, $37 \%$ vs $10 \%$ blood transfusion was required in open surgery and $\mathrm{PCNL}$ respectively.

The Benchmark paper based on early days of PCNL in UK reported transfusion rates of between 29 and 55\%. [11] However, in a recent study on PCNL Stephene R et al. [12]. in 2013, reveals that much less no. of patients (3.8\%) required blood transfusion, this may be due to the fact that our study was very early experience of PCNL in this institute and the technique was performed on the large stone, $(>2 \mathrm{~cm})$. All percutaneous renal haemorrhage was successfully managed conservatively with transfusion.

\section{Conclusion:}

PCNL is relatively safe \& better treatment option than open surgery in the treatment of large renal calculi. It has definite advantages of statistically less peroperative bleeding and lower morbidity, inspite of some limitations 
like small sample size, purposive sampling, surgery was not done by single surgeon \& stone composition was not considered here. Further research should be conducted on two well matched comparative groups of large sample size to establish the findings of the present study.

Conflict of Interest: None declared

\section{References}

1. Fernstrom I, Johansson B. Percutaneous pyelolithotomy: A new extractionTechnique. Surgical management of upper urinary tract calculi.Champbell's Urology; 1976. 9th ed. Philadelphia: Saunders Elsevier: 502-510.

2. Stoller ML, Tangaho EA, Aninch JW, Botton DM. Urinary stone Disease. Smith's General Urology, 15thed; Singapur,McGraw-Hill2000: 551-562.

3. Lingeman JE, Newmark JR, Smith AD, Wong MY. Classification and management of staghorn calculi, Controversies in Endourology, Philadelphia 2002: WB Saunders.

4. Salam MA, Urinary stone disease, Principles and practice of urology, 1st ed. Dhaka, MAS publication 2002

5. Rashid HU, Rahman H. Prevelance, clinical presentation and renal stones disease in a renal out patient clinic at Dhaka. Bangladesh renal Journal 1988; 7: 52-56.

6. Assimos DG, Boyce WH, Harrison LH, A comparison of anatrophicnephrolithotomy and percutaneous nephrolithotomy with or without extracorporeal shock wave lithotripsy for the management of patients with staghorn calculi. The Journal of Urology 1991; 145(3): 701-714.

7. Brannen GE, Bush WH. Kidney stone removal: Percutaneous vssurgical lithotomy. The Journal of Urology 1985; 133: 1037-1038

8. Wong Y C. Evolving technique of percutaneous nephrolithotomy in a developing country: Singapore general hospital experience. Journal of Endourology 1998; 12(5): 397-401.

9. Alkohlani KM, Shoker AA, Mosbah A, Mohsen T et al. Treatment of complete staghorn stones: A prospective randomized comparison of open surgery vs percutaneous nephrolithotomy. The Journal of Urology 2005; 173(2): 469-473.

10. Rassweiler JJ, Rener $\mathrm{C}$. The management of complex renal stones : British Journal of Urology; 2000: 86: 919.

11. Jones DJ, Russel GL, Kellett MJ, Wickham JE. The changing practice of percutaneoys stone surgery. Review 1000 cases 1981- 1988. BJU 1990; 66: 1-5.

12. Stephen R K, Richard J. Blood transfusion, embolization and nephrectomy after percutaneous nephrolithotomy(PCNL). BJU International 2013; 111: 624-632.

Abbreviations:

ESWL : Extra corporeal shackwave lithotripsy

PCNL : Percutaneous Nephrolithotomy

RCT : Randomised Controlled Trial 